\title{
RMetS
}

Royal Meteorological Society

\section{Two major modes of variability of the East Asian summer monsoon}

\author{
Xuguang Sun, ${ }^{\mathrm{a}}$ Richard J. Greatbatch, ${ }^{\mathrm{b} *}$ Wonsun Park $^{\mathrm{b}}$ and Mojib Latif ${ }^{\mathrm{b}}$ \\ ${ }^{a}$ School of Atmospheric Sciences, Nanjing University, China \\ ${ }^{\mathrm{b}}$ Leibniz-Institut für Meereswissenschaften, IFM-GEOMAR, Kiel, Germany \\ ${ }^{*}$ Correspondence to: Richard J. Greatbatch, Leibniz-Institut für Meereswissenschaften, IFM-GEOMAR, Düsternbrooker \\ Weg 20, 24105 Kiel, Germany. E-mail: rgreatbatch@ifm-geomar.de
}

\begin{abstract}
We study the two primary modes of variability associated with the East Asian summer monsoon, as identified using a multivariate Empirical Orthogonal Function (EOF) analysis. The second mode is shown to be related to changes in intensity of the South Asian High at $100 \mathrm{hPa}$ while, consistent with previous work, the first mode is associated with an index for the shear vorticity of the $850 \mathrm{hPa}$ zonal wind over the monsoon region. We show that a linear, dry dynamical model, when driven by the diabatic heating anomalies associated with each mode, can reproduce many of the anomalous circulation features, especially for the first EOF and in the lower troposphere. The model results indicate the importance of diabatic heating anomalies over the tropical Indian Ocean in the dynamics of both modes, especially EOF-1, and illustrate the role of local diabatic feedback for intensifying the circulation anomalies; in particular, the subtropical anticyclonic anomalies that are found in the positive phase of both modes, and the circulation anomaly associated with the Meiyu/Changma/Baiu rain band. A running cross-correlation analysis shows that the second EOF is consistently linked to both the decaying and the onset phase of El Niño/Southern Oscillation (ENSO) events throughout the study period (1958-2001). We attribute the connection in the onset phase to zonal wind anomalies along the Equator in the west Pacific associated with this mode. On the other hand, a link between the first EOF and ENSO is found only in the post-1979 period. We note also the role of sea-surface temperature anomalies in the tropical Indian Ocean in the dynamics of EOF-1, and a link to the variability of the Indian summer monsoon in the case of EOF-2. Copyright (c) 2010 Royal Meteorological Society
\end{abstract}

Key Words: South Asian High; diabatic heating; El Niño

Received 25 October 2009; Revised 24 February 2010; Accepted 12 April 2010; Published online in Wiley InterScience 28 May 2010

Citation: Sun X, Greatbatch RJ, Park W, Latif M. 2010. Two major modes of variability of the East Asian summer monsoon. Q. J. R. Meteorol. Soc. 136: 829-841. DOI:10.1002/qj.635

\section{Introduction}

The East Asian Summer Monsoon (hereafter EASM) is a major feature of the June/July/August (JJA) global atmospheric circulation (see Ding and Chan (2005) for a review). As noted by Rodwell and Hoskins (2001), the rainfall associated with the monsoon sustains about half the human population; clearly, understanding the variability of the EASM is a problem of major socio-economic importance. Many different indices have been proposed for measuring the strength of the EASM. In an attempt to rationalize the different approaches, Wang et al. (2008a) carried out a multivariate Empirical Orthogonal Function (EOF) analysis on a set of six meteorological fields for the months of JJA (precipitation, the zonal and meridional winds at 850 and $200 \mathrm{hPa}$, and sea-level pressure). For 
positive values of the principal component (PC) time series, the first two EOFs feature an anticyclonic anomaly over the subtropical western Pacific at $850 \mathrm{hPa}$ (to compare with Wang et al., 'positive' should be read as 'negative' for the second EOF). In the case of the first EOF, the associated meridional flow anomaly extends northward across the neighbouring continent as far as the Yangtze River valley region where, in the positive phase, there is a band of anomalously high precipitation that also extends across Korea and Japan. Summer rainfall in this area is called the 'Meiyu' in China, the 'Changma' in Korea and the 'Baiu' in Japan. In the case of the second EOF, the anomalous meridional flow extends much further north leading, in the positive phase, to anomalously high precipitation over northern China.

In the search for a simple characterization of the first EOF, Wang et al. (2008a) noted that the PC time series is highly correlated with the shear vorticity index introduced by Wang and Fan (1999) (hereafter the WF index). The WF index is defined as the zonal wind at $850 \mathrm{hPa}$ in the region $\left(5^{\circ}-15^{\circ} \mathrm{N}, 90^{\circ}-130^{\circ} \mathrm{E}\right)$ minus that in the region $\left(22.5^{\circ}-32.5^{\circ} \mathrm{N}, 110^{\circ}-140^{\circ} \mathrm{E}\right)$. The WF index gives a simple way of measuring the variability associated with the first EOF and facilitates real-time monitoring of the monsoon. In the same spirit, we show in the present paper that the second EOF is closely related to the variability in the intensity of the South Asian High (SAH) at $100 \mathrm{hPa}$, providing a second simple index with which to monitor another independent aspect of the monsoon's variability. The SAH has previously attracted attention in its own right (e.g. Zhang et al., 2005) because of its dominance in the summer atmospheric circulation over south Asia at $100 \mathrm{hPa}$ (see Figure 1).

To understand the dynamics of the variability of the EASM, we take as our starting point the work of Hoskins and Rodwell (1995). These authors showed that the mean JJA circulation associated with the EASM, including the South Asian High, is captured by a nonlinear dry, dynamical model driven by diabatic heating diagnosed from European Centre for Medium-Range Weather Forecasts (ECMWF) analyses. A linear version of the model forced by diabatic heating, but with no orography, is also quite successful at capturing the mean circulation, especially in the upper troposphere. These results inspired us to run a dry, linear model, in this case linearized about the mean JJA circulation and driven by the

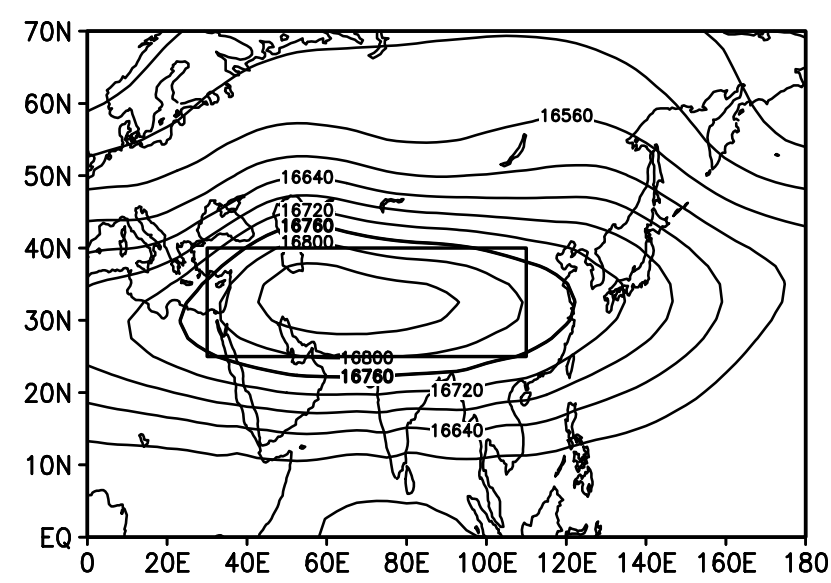

Figure 1. Climatological geopotential height at $100 \mathrm{hPa}$ for JJA, unit: m. The contour line for $16760 \mathrm{~m}$ is thickened to indicate the South Asian High. The South Asian High Index (SAHI) is defined as the time series of anomalies in geopotential height averaged over the area in the black box. diabatic heating anomalies that go along with the first two multivariate EOF modes. Our results show that the linear model can capture the circulation anomalies associated with both EOFs, especially in the lower troposphere and with generally better performance for the first than the second EOF. Since the diabatic heating anomalies are dominated by the latent heat release due to precipitation, it seems that a positive feedback exists in which the diabatic heating drives the circulation anomalies that in turn, when added to the mean circulation, feed the moisture convergence that drives the precipitation anomalies.

Another interesting aspect of the monsoon is the possibility that the variability might be linked to the El Niño/Southern Oscillation (ENSO). Wang et al. (2008a) associate the first EOF with the decaying phase of ENSO events and the second EOF with the developing phase. As we shall see, a feature of the second EOF is the presence of zonal wind anomalies along the Equator in the western Pacific, a feature that is consistent with the idea that variability associated with this EOF helps initiate ENSO events. Regarding the first EOF, we shall see that the link with ENSO has not been robust throughout the 44 years of our analysis and has only been significant during the years since 1979 studied by Wang et al. (2008a). A change in the relationship between ENSO and East Asian climate after the mid-1970s has also been noted by Xie et al. (2010). The mid1970 s is often associated with a climate or regime shift (Miller et al., 1994), as many climate variables exhibited a change in behaviour at that time. On the other hand, the link between both EOFs and the diabatic heating anomalies appears to be robust throughout the study period. Of particular interest are the anticyclonic circulation anomalies over the western subtropical Pacific associated with the positive phase of both EOFs. Anticyclonic anomalies in this area have been linked to anomalously high sea-surface temperature (SST) in the tropical Indian Ocean (e.g. Watanabe and Jin, 2003; Yang et al., 2007; Li et al., 2008; Xie et al., 2009, 2010), a link we investigate further here. It should also be noted that Rodwell and Hoskins (2001) have argued that the subtropical anticyclones seen in the summer mean circulation are themselves at least partly maintained by the forcing of the atmosphere by the diabatic heating released by the monsoon rains. It follows that fluctuations in the strength of the monsoon might also lead to fluctuations in the strength of these anticyclones.

The plan of the paper is as follows. Section 2 focuses on the multivariate EOF analysis and the link between the second EOF and the variability of the South Asian High. Then in section 3 we describe the use of the diabatic heating anomalies for each of the first two EOFs as forcing for the linear, dry dynamical model described by Watanabe and Kimoto $(2000,2001)$. The results illustrate the importance of anomalous diabatic heating over the tropical Indian Ocean in the dynamics of both modes. Section 4 discusses the link between the first two EOFs and ENSO, and how this connection has changed over the study period, 1958-2001. Finally, section 5 provides a summary.

\section{The multivariate EOF analysis}

The primary dataset we use is the ERA-40 reanalysis product from ECMWF (Uppala et al., 2005) for the months of June, July and August. Similar to Wang et al. (2008a) (see also Liu et al., 2008), a multivariate (MV) EOF analysis is carried 

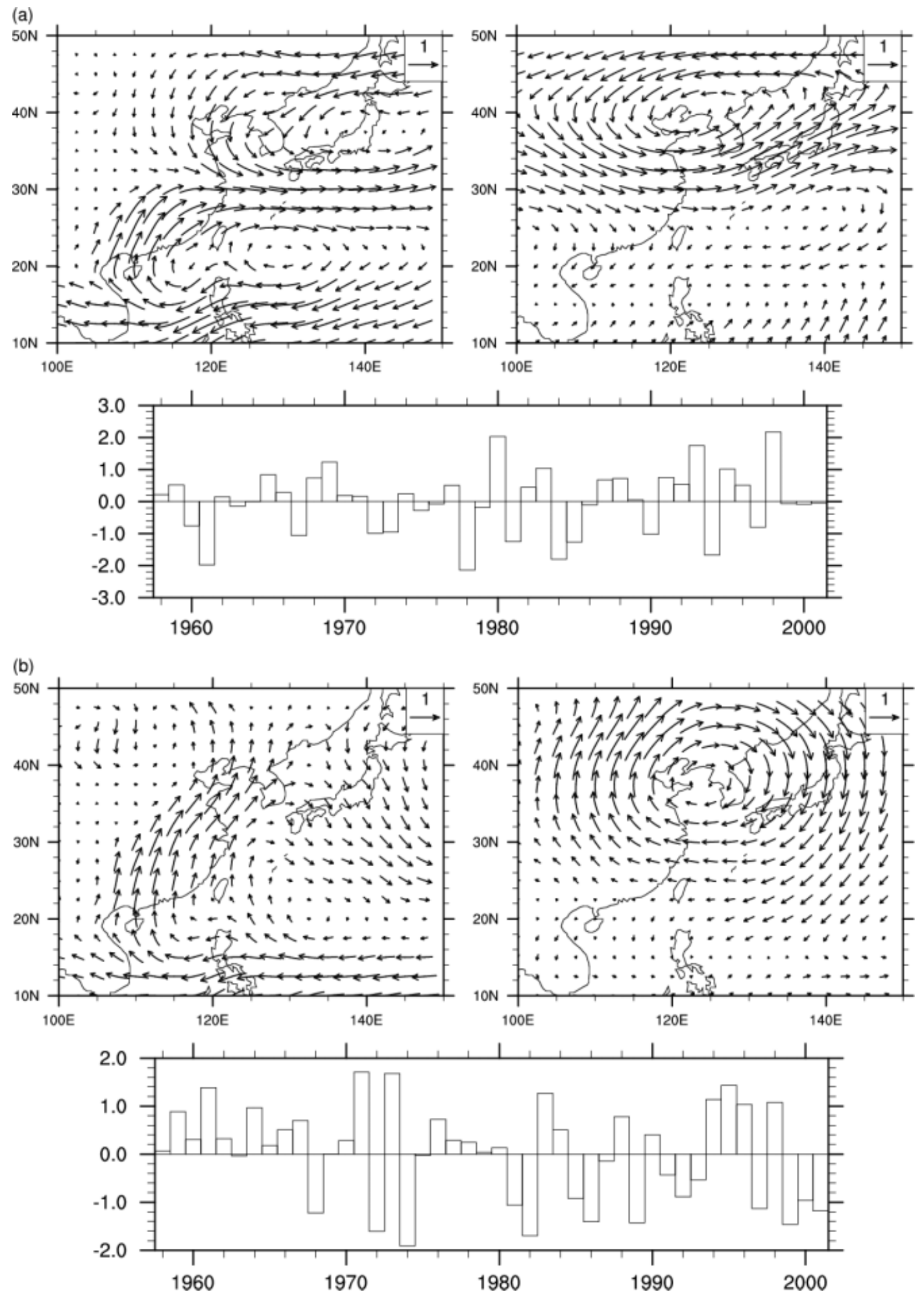

Figure 2. Spatial patterns and time series of (a) the first and (b) the second MV-EOF mode of the East Asian summer 850 hPa winds (vector in the left panels) and $200 \mathrm{hPa}$ winds (vector in the right panels). The first and second MV-EOF modes explain $20.2 \%$ and $11.6 \%$ of total variance, respectively. The reference arrow in the top right corner corresponds to $1 \mathrm{~m} \mathrm{~s}^{-1}$. The EOFs are computed using data from the geographic region shown in the figures.

out on JJA averages of zonal and meridional wind at 850 and $200 \mathrm{hPa}$ over the domain bounded by $10^{\circ}-50^{\circ} \mathrm{N}$ and $100^{\circ}-150^{\circ} \mathrm{E}$ (see Figure 2) for the years $1958-2001$, the period covered by the reanalysis. The MV-EOF analysis method is described in detail in Wang (1992); in particular, prior to the analysis, the interannual anomalies for each variable are normalized by dividing by the area-averaged standard deviation. Note that Wang et al. (2008a) also include precipitation and sea-level pressure data in their EOF analysis, and that their analysis covers only the period 1979-2006. As such, the EOFs resulting from our analysis may show some differences from those obtained by Wang et al. (2008a). Nevertheless, our first two EOFs are very similar to those from Wang et al. (2008a) and account for $20.2 \%$ and $11.6 \%$ of the total variance, respectively (compared to $21.1 \%$ and $11.1 \%$ in Wang et al. (2008a)). The 
spatial patterns and associated principal component (PC) time series of the first two EOFs are shown in Figure 2 and are quite similar to those found by Wang et al. (2008a) (note that for the second EOF, the sign is reversed from Wang et al. (2008a)). In the following, we also make use of precipitation data from 1958-2001 taken from the monthlygridded precipitation dataset CRU TS 2.1 of the Climatic Research Unit at the University of East Anglia (Mitchell and Jones, 2005).

Looking at the first EOF (Figure 2(a)), we begin by noting that the spatial anomalies at both $850 \mathrm{hPa}$ and $200 \mathrm{hPa}$ are similar to those associated with the negative phase of the so-called Pacific-Japan (PJ) pattern (Nitta, 1987; Kosaka and Nakamura, 2006). At $850 \mathrm{hPa}$, the circulation anomalies are dominated, in the positive phase, by a dipole pattern with an anticyclonic anomaly in the subtropical western Pacific and a cyclonic anomaly centred near Japan. The confluence zone associated with these two anomalous circulations is associated with enhanced precipitation along the Yangtze River valley near $30^{\circ} \mathrm{N}$ (see Figure 3(a)), corresponding to the 'Meiyu' rains. At $200 \mathrm{hPa}$, the circulation anomalies, again in the positive phase, are dominated by the cyclonic anomaly, now displaced to the west and centred over the Bohai Sea between China and Korea. Looking at the second EOF (Figure 2(b)), in the positive phase, an anticyclonic anomaly at $850 \mathrm{hPa}$ is again evident in the western subtropical Pacific. On the other hand, the southerly $850 \mathrm{hPa}$ wind anomalies associated with this mode extend much further north than for EOF-1 and are associated, in the positive phase, with enhanced rainfall over northern China (see Figure 3(b)). At $200 \mathrm{hPa}$, a large anticyclonic anomaly is centred at $200 \mathrm{hPa}$ over the Bo Hai Sea in the positive phase, in contrast to the cyclonic anomaly associated with the first mode. This anticyclonic anomaly forms part of a wave train at $200 \mathrm{hPa}$ that also includes an anticyclonic anomaly (positive phase) that projects onto the South Asia High shown in Figure 1, as discussed further in the next paragraph. The second mode is also associated, in the positive phase, with enhanced rainfall across the whole of the Indian subcontinent, indicating a link to the variability of the Indian summer monsoon. Indeed, the correlation between the principal component time series of EOF-2 and the All-India Rainfall Index (AIRI) (Parthasarathy et al., 1995 ) is 0.59 , significantly different from zero at the $99 \%$ confidence level. The correlation between the AIRI and the PC time series for EOF-1 is only -0.13 .

Figure 4 shows the time series of the WF-index (Wang and Fan, 1999) and what we call the South Asian High Index (SAHI), together with the PC time series for both EOFs. The SAHI is the time series of anomalies in the JJA mean $100 \mathrm{hPa}$ geopotential height averaged over the area shown in Figure 1. It is clear that the WF-index and the time series for the first EOF are closely related (correlation 0.82, significant at the $99 \%$ level), in agreement with the findings of Wang et al. (2008a). It is also clear that the SAHI is closely related, though not identical, to the PC time series for the second EOF (correlation 0.55, significant at the 99\% level). This is the first of the new results in this paper. Monitoring of the SAHI provides a simple way to measure the time variation of EOF-2. Note also that there is no correlation between the PC time series for EOF-1 and the SAHI (the correlation is -0.01 ), with the implication that the variability associated with the SAHI is indeed distinct from that associated with EOF-1. Regressing atmospheric circulation fields against the

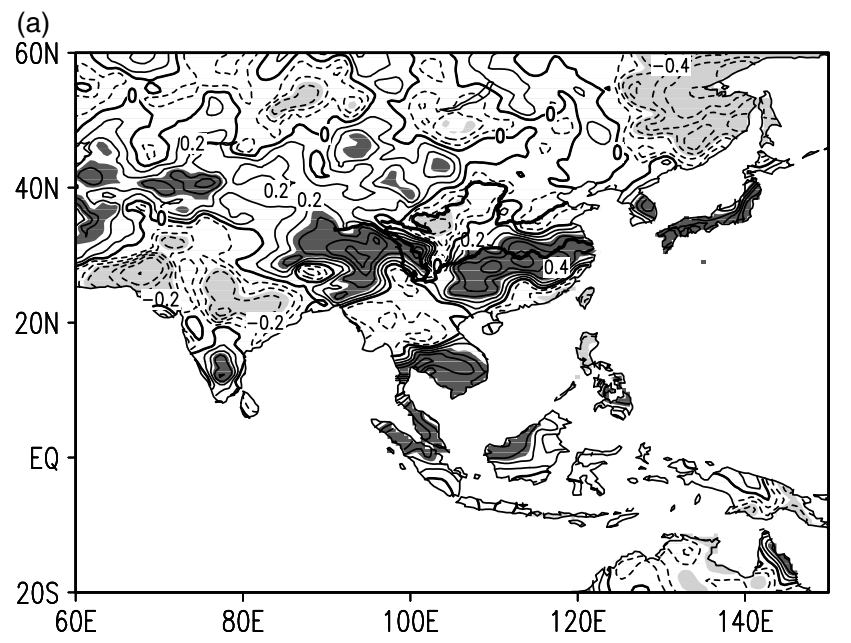

(b)

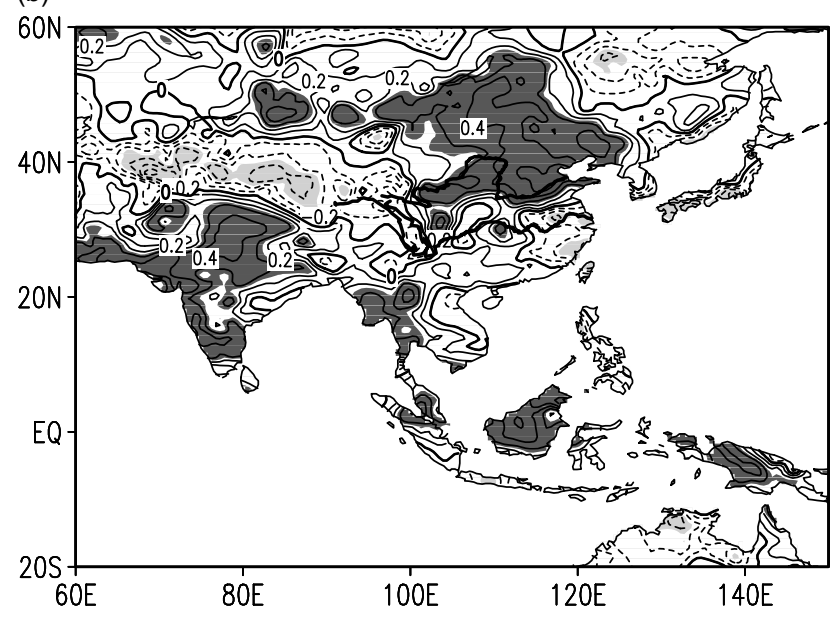

Figure 3. Correlation of JJA precipitation with (a) PC1 and (b) PC2 of the MV-EOFs shown in Figure 2. Shaded areas indicate correlation above the $90 \%$ confidence level.

SAHI reveals similar patterns to those shown for EOF-2 in Figure 2(b). An interesting aspect of the SAHI (and to some extent EOF-2) is that variations in this index capture variations in the Somali Jet off eastern Africa (not shown), an important circulation feature for feeding moisture into the Indian subcontinent during the summer monsoon season.

Figure 5 shows the pattern of the diabatic heating anomalies associated with the positive phase of each EOF integrated over the depth of the troposphere from $925 \mathrm{hPa}$ to $150 \mathrm{hPa}$. The total diabatic heating was first diagnosed from 6-hourly ERA-40 data as a residual in the thermodynamic equation, then averaged over JJA in each year, and then regressed against the two PC time series to obtain the patterns shown in Figure 5. It is the corresponding three-dimensional (3-D) patterns of diabatic heating that are used in the next section to drive the linear dynamical model. The positive phase of both EOFs features anomalous diabatic cooling in the region of the anomalous anticyclonic circulation anomalies noted when discussing Figure 2. In the case of EOF-1, this diabatic cooling anomaly is surrounded by diabatic heating anomalies, notably to the north in association with the anomalous precipitation in the band from the Yangtze River valley across Korea to Japan (the 'Meiyu', 'Changma' and 'Baiu' rains). In the case of the second EOF, the diabatic cooling anomaly extends southeastward towards the Equator and there are again surrounding diabatic heating 
(a)

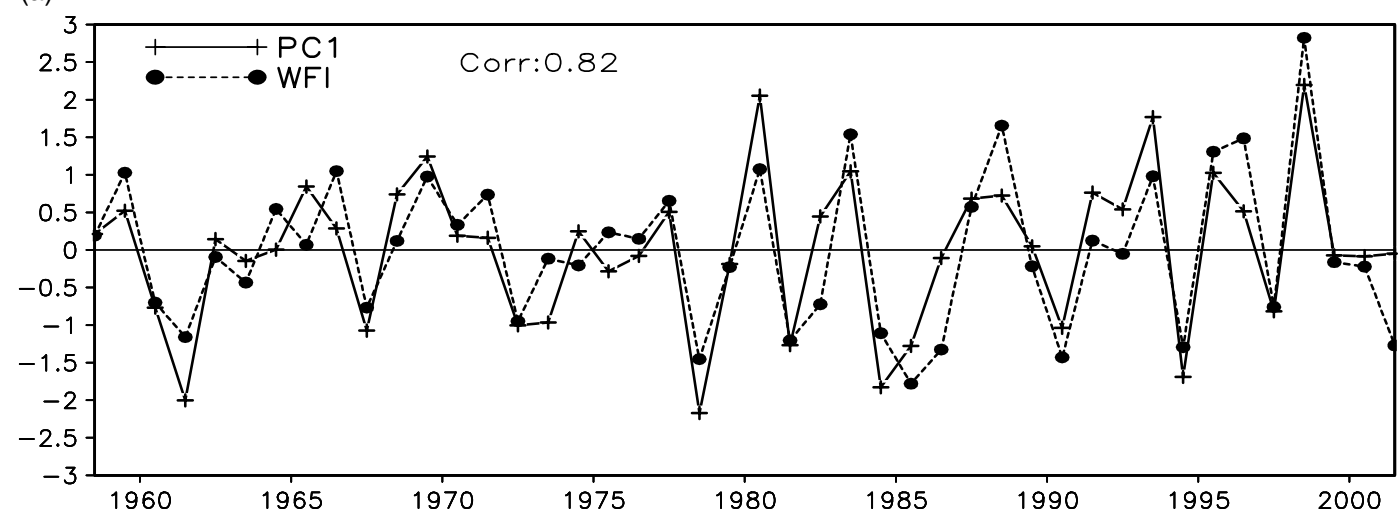

(b)

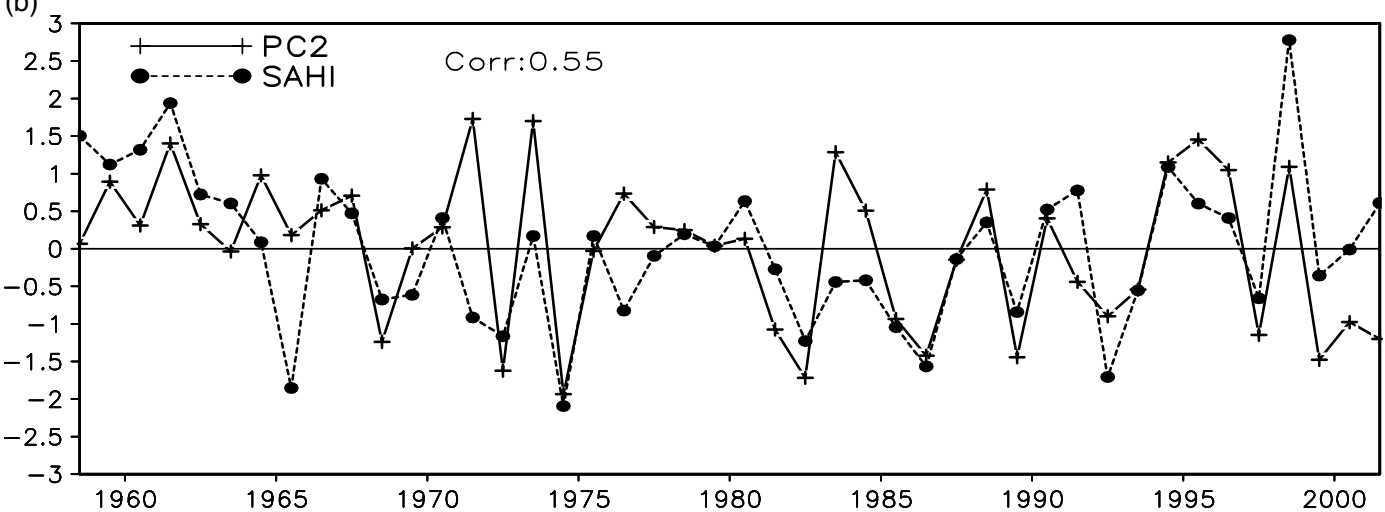

Figure 4. Time series for (a) the Wang and Fan index (WFI, dotted line), PC1 (solid line), (b) South Asian High index (SAHI, dotted line) and PC2 (solid line). The correlation coefficient between WFI and PC1 is 0.82 , and 0.55 between SAHI and PC2, significantly different from zero at the $99 \%$ confidence level.

anomalies, especially over the Indian Ocean/maritime continent region. Perhaps not surprisingly, given the link we have established between EOF-2 and the South Asian High Index, the pattern of enhanced and reduced diabatic heating associated with this mode is quite similar to the pattern of enhanced and reduced precipitation associated with the variations in the strength of the South Asian High found by Zhang et al. (2005) (their Fig. 6b).

\section{The linear model}

The model is the same as that used by Watanabe and Kimoto $(2000,2001)$ except that here the model set-up is basically as in Lu and Lin (2009). In particular, the model integrates the dry primitive equations linearized about the mean JJA climatology obtained from the ERA-40 reanalysis and includes orography with realistic amplitude. The horizontal resolution of the model is T42 (corresponding to roughly $2.8^{\circ}$ by $2.8^{\circ}$ in latitude and longitude) and in the vertical there are 20 unevenly spaced sigma (orography following) levels. The model includes a horizontal (vertical) diffusion, Rayleigh friction and Newtonian damping. The damping time-scale for both the Rayleigh friction and the Newtonian damping is set at 1 day for $\sigma \geqslant 0.9$ and $\sigma \leqslant 0.03$, and 20 days at the intermediate levels apart from the two levels with $0.8 \leqslant \sigma \leqslant 0.9$. In order to smoothly join the region of high damping near the bottom with the interior, the damping time-scale at these two levels is set to 5 and 15 days respectively. The model is forced by the diabatic heating anomalies associated with the positive phase of each mode (Figure 5) and is integrated for 30 days. A steady state is reached after about 15 days of integration. Here we show the results at day 20.

Figure 6 shows the model-computed circulation anomalies at $850 \mathrm{hPa}$ driven by the diabatic heating anomalies associated with the positive phase of each EOF together with the circulation anomalies obtained from the ERA-40 reanalysis by regression against the corresponding PC time series. Looking at the first EOF, the model reproduces the anticyclonic anomaly near $20^{\circ} \mathrm{N}$ together with the alternating cyclonic and anticyclonic anomalies to the north. At $200 \mathrm{hPa}$ (not shown), the model captures anomalous cross-equatorial flow between $90^{\circ} \mathrm{E}$ and $120^{\circ} \mathrm{E}$ found in the reanalysis. However, in the ERA-40 data the circulation anomalies become increasingly equivalent barotropic in the middle latitudes (see Kosaka and Nakamura (2006), who note the northward tilt of the anomalies in middle latitudes), a feature that is much less evident in the model, presumably because the model lacks the eddy-mean flow interaction with the upper tropospheric westerly jet stream. We have also forced the model by the diabatic heating anomalies confined to the regions shown in Figure 7. Forcing the model using the diabatic cooling anomaly in the subtropical western Pacific reproduces the co-located anticyclonic circulation anomaly but fails to capture the cyclonic anomaly to the north (Figure 7(a) and (b)). To reproduce the latter, we must add the positive diabatic heating anomaly associated with the anomalous Meiyu/Changma/Baiu rainfall to the model forcing (see Figure 7(c) and (d)). It should be noted that the model response to the Meiyu/Changma/Baiu heating anomaly is similar to that found by Lu and Lin (2009) using idealized heat forcing. Turning now to the positive phase of EOF-2, the model again captures the anticyclonic 

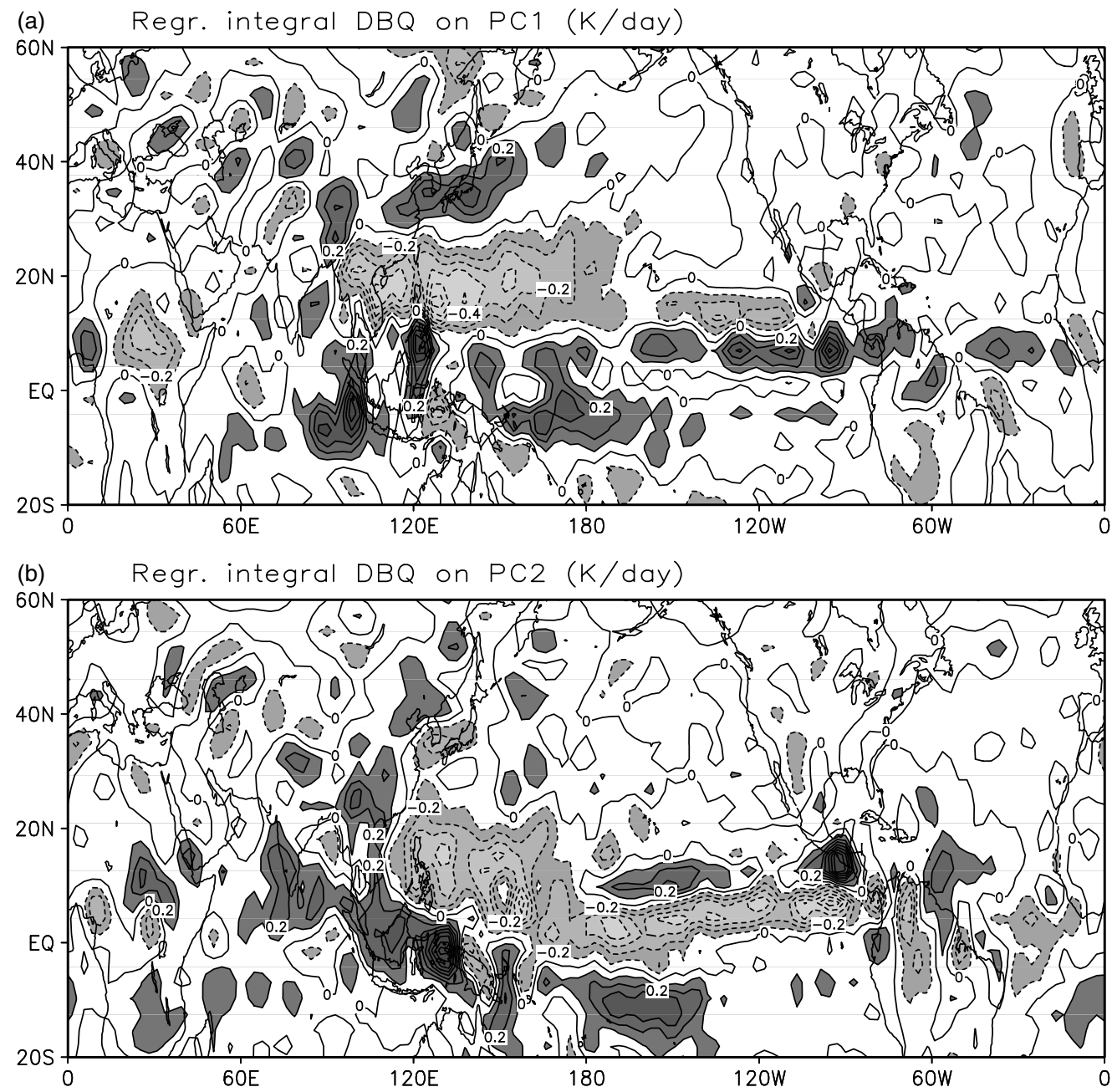

Figure 5. Regression patterns of the diabatic heating anomalies (DBQ) associated with (a) EOF-1 and (b) EOF-2, integrated over the depth of the troposphere from $925 \mathrm{hPa}$ to $150 \mathrm{hPa}$. Shaded areas in dark grey and light grey colours indicate the regression value above $0.1 \mathrm{~K} /$ day and below $-0.1 \mathrm{~K} /$ day, respectively. Dark/light grey indicates anomalous heating/cooling associated with the positive phase of each EOF.

anomaly at $850 \mathrm{hPa}$ but with rather stronger amplitude than in the observations. As before, the anticyclonic anomaly is reproduced when the co-located diabatic heating anomaly drives the model (Figure 8(a) and (b)). At $200 \mathrm{hPa}$ (not shown), the model again captures cross-equatorial anomalous flow between $90^{\circ} \mathrm{E}$ and $120^{\circ} \mathrm{E}$ but fails to capture the anticyclonic anomaly centred over Korea in the reanalysis data (see Figure 2(b)) where, instead, the model puts a cyclonic circulation anomaly.

To understand the origin of the two EOFs, Figure 9 compares the circulation anomalies at $500 \mathrm{hPa}$ in the ERA40 data (Figure 9(a) and (b)) with those from two model runs: (1) driven by the global diabatic heating anomaly (Figure 9(c) and (d)), and (2) driven by the diabatic heating anomaly confined to the tropical Indian Ocean and maritime continent region only (Figure 9(e) and (f), and note that the contour interval in these panels is $1 / 5^{\text {th }}$ that in the upper panels), all cases corresponding to the positive phase of each EOF. In the case of EOF-1 (the left panels), the anomalous diabatic heating over the tropical Indian Ocean drives a wave train which extends into the middle latitudes with the positive and negative height anomalies roughly corresponding to those in both the full forcing case and the ERA-40 data, but with somewhat reduced amplitude. In particular, comparing Figure 9(c) and (e), we see similarly located anticyclonic anomalies between $20^{\circ} \mathrm{N}$ and $35^{\circ} \mathrm{N}$ over China and even a weak band of anomalies to the north corresponding to the location of the negative anomalies in Figure 9(a) and (c) associated with the Meiyu/Changma/Baiu rain band. This experiment argues strongly that the variability associated with EOF1 has its origin in the tropical Indian Ocean, consistent with the work of others, in particular Yang et al. (2007), Li et al. (2008) and Xie et al. (2009, 2010). These authors have shown the importance of SST anomalies in the tropical Indian Ocean for driving a teleconnection pattern over East Asia similar to our EOF-1 (and also the PJ-pattern of Nitta (1987)). The results shown in Figure 7(b) and (d) further support this view. In particular, from Figure $7(\mathrm{~b})$ and (d) we see that the amplitude of the alternating cyclonic and anticyclonic circulation anomalies can be greatly increased by the feedback from the local, circulation-induced diabatic heating (i.e. subsidence in the anomalous subtropical high leading to reduced precipitation and hence reduced diabatic heating, with the opposite being true in the Meiyu rain band to the north). The local amplification effect is demonstrated by Xie et al. (2009) for the case of subtropical anticyclonic anomalies driven by warm SST anomalies in the tropical Indian Ocean (see also Watanabe and Jin (2003) for an example from the winter season).

In the case of EOF-2, a very similar wave train as for EOF-1 is excited by the forcing over the Indian Ocean 

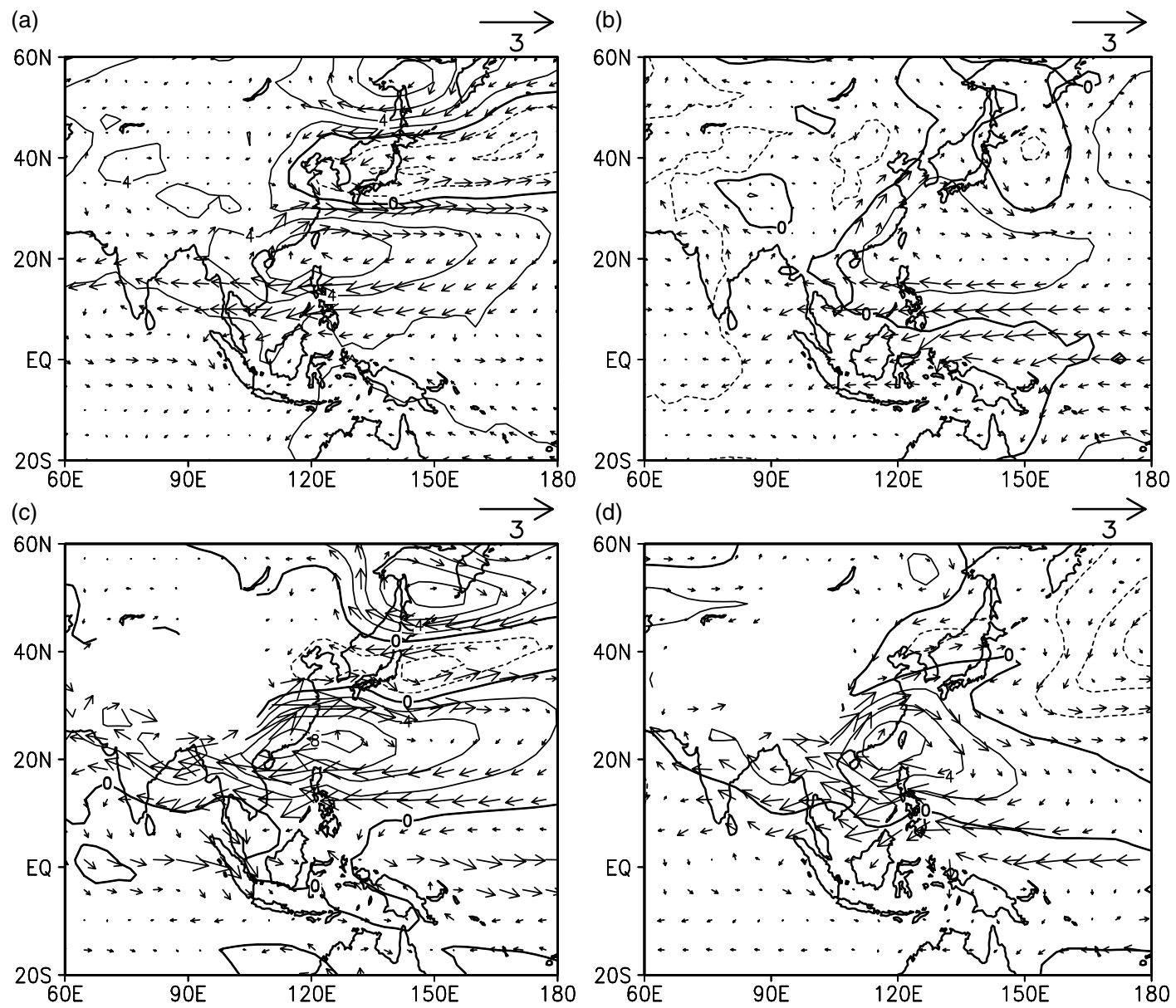

Figure 6. Regression patterns of geopotential height and wind field associated with (a) EOF-1 and (b) EOF-2 at 850 hPa in the ERA-40 reanalysis data, and the geopotential height and wind field response in the linear, dry dynamical model to the global 3-D diabatic heating regressed on (c) PC1 and (d) PC2 of the MV-EOFs. Contour lines indicate geopotential height, and vectors indicate the wind field. Contour interval is $2 \mathrm{~m}$. The reference arrow in the top right of each panel corresponds to $3 \mathrm{~m} \mathrm{~s}^{-1}$.
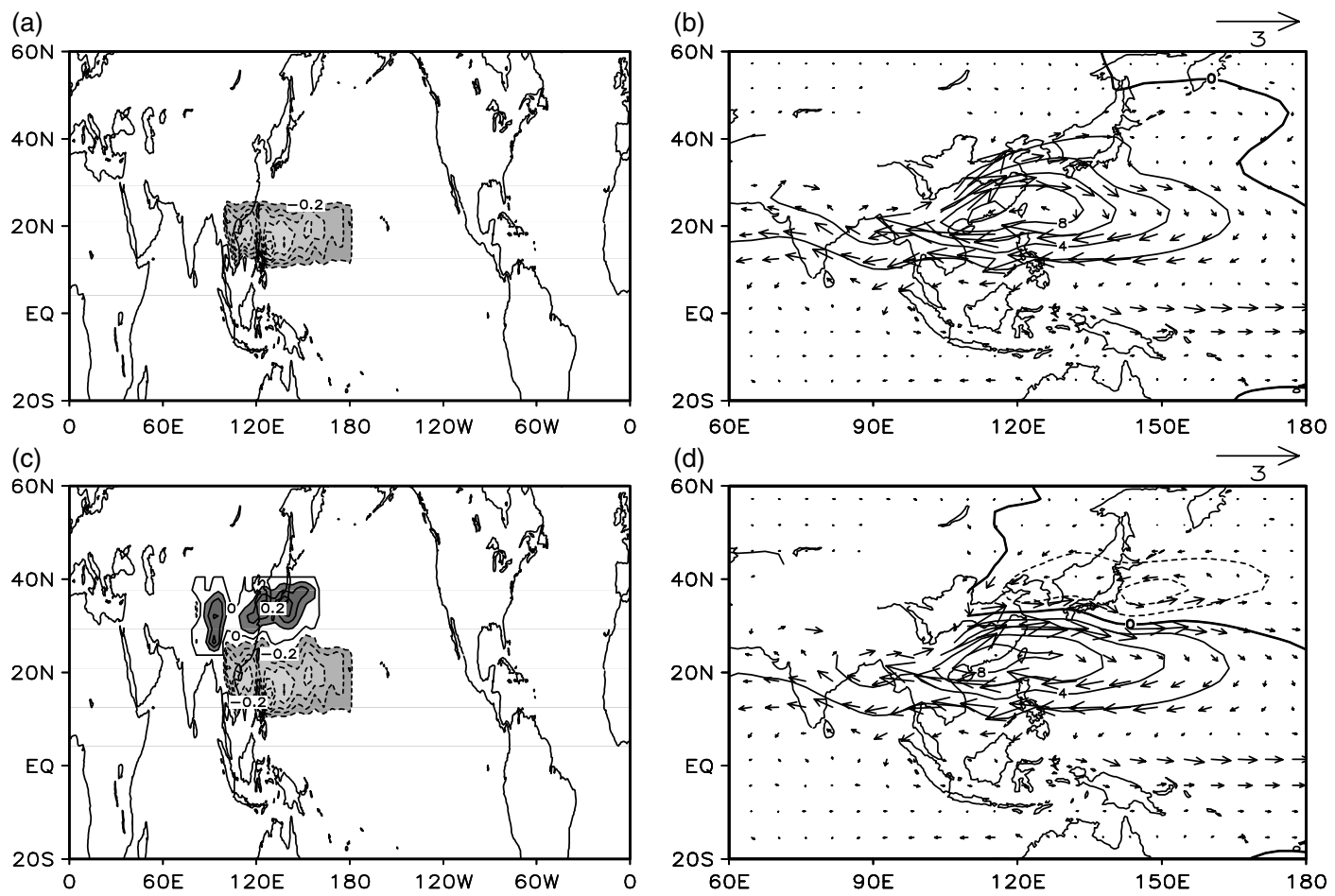

Figure 7. Left column: Same as Figure 5 except showing the regressed diabatic heating anomalies associated with EOF-1 confined to (a) the subtropical western Pacific and (c) the subtropical western Pacific and subtropical East Asia. Right column: Same as Figure 6 but showing the geopotential height and wind field response in the linear, dry dynamical model to the corresponding 3-D diabatic heating anomalies shown in the left column. It should be noted that the left and right columns are plotted over different domains. 
(a)

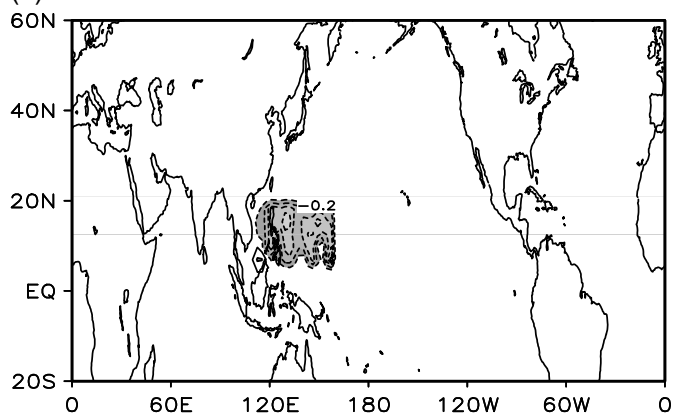

(c)

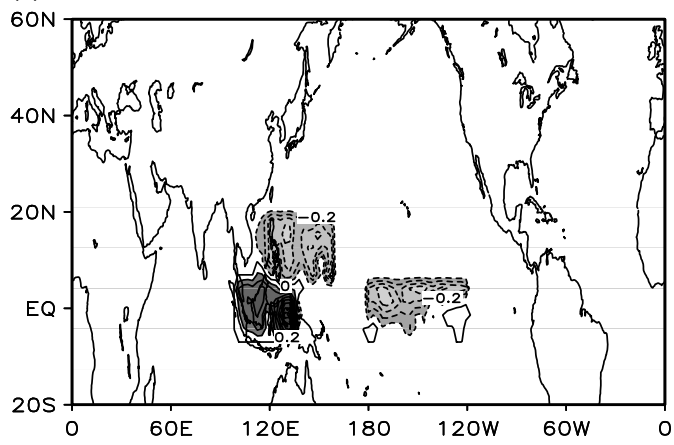

(b)

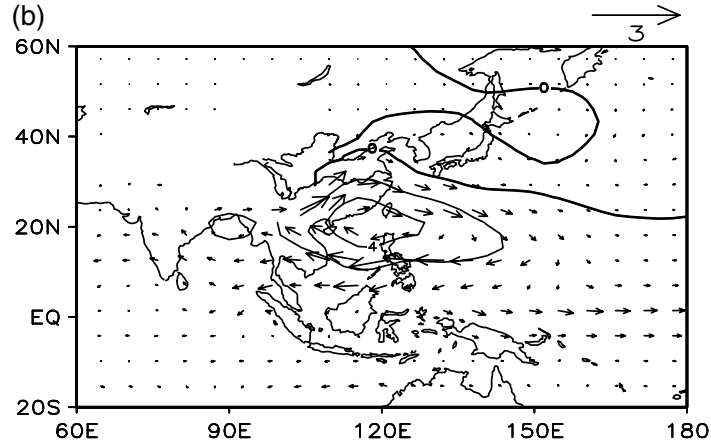

(d)

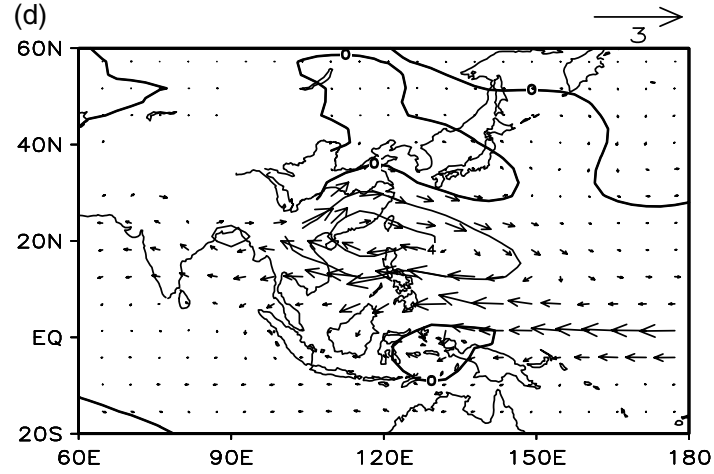

Figure 8. Same as Figure 7 except for diabatic heating anomalies associated with EOF-2.

and the maritime continent combined (cf. Figure 9(e) and (f)). In the Tropics and subtropics, the centres of action again largely coincide with those when the full forcing is used, but with reduced amplitude. In particular, we again see an anticyclonic anomaly in the subtropical western Pacific, a feature that is considerably enhanced in amplitude when forcing the model using the co-located diabatic cooling anomaly (Figure 8(c) and (d)), showing that the amplification mechanism discussed in connection with EOF-1 operates here as well. However, at higher latitudes, the agreement between the model and the regression patterns from the ERA-40 data deteriorates markedly (not only at $500 \mathrm{hPa}$ but also at $850 \mathrm{hPa}$ - see Figure 6). Indeed, while it is clear that anomalous diabatic heating over the Indian Ocean/maritime continent region is important in the dynamics of both modes, the main difference between the two EOFs occurs at middle latitudes and appears to be related to the way in which these two circulation anomalies interact with the westerly jet stream. That the midlatitude westerlies play a role in the dynamics of the PJ-pattern (and hence EOF-1) is clear from the work of Kosaka and Nakamura (2006) and Sampe and Xie (2010). However, the role of the midlatitude westerly in the dynamics of EOF-2 remains a topic for future research.

While the major differences between EOF-1 and EOF-2 occur in middle latitudes, there are also subtle differences in the Tropics. We noted when discussing Figure 5 that the region of diabatic cooling associated with the subtropical anticyclonic anomalies extends southward into the equatorial region in the case of EOF-2 but not EOF-1. It turns out that to obtain the correct flow pattern along the Equator, it is necessary to include the diabatic forcing from the equatorial region. So, for example, when forcing only with the diabatic cooling anomaly associated with the subtropical anticyclonic circulation anomaly (Figure 8(a) and (b)), the anomalous zonal flow along the Equator at $850 \mathrm{hPa}$ has the opposite direction compared to the observations. To capture the correct flow direction, it is necessary to include the diabatic heating anomalies along the Equator (Figure 8(c) and (d)). In particular, the region of heating anomaly centred at $120^{\circ} \mathrm{E}$ forces a Gill-type response (Gill, 1980) in which anomalous westward flow is drawn into the heating area from the east in the wake of a Kelvin wave propagating eastward along the Equator. The anomalous westward flow along the Equator is, in turn, enhanced by the Rossby wave response to the diabatic cooling anomaly further east, between $180^{\circ} \mathrm{W}$ and $120^{\circ} \mathrm{W}$. In the introduction, we noted that EOF-2 has been associated by Wang et al. (2008a) with the onset phase of an ENSO event and we note that for the positive phase of the EOF2 considered here, the zonal flow anomalies produced by the model, and as found in the observational analysis, are consistent with the onset phase of a La Niña event, an issue we explore further in the next section.

\section{The link between the two EOFs, ENSO and Indian Ocean SST anomalies}

Wang et al. (2008a) associate the positive phase of EOF-1 with the declining phase of El Niño and that of EOF-2 with the onset phase of El Niño (in our case, since the sign is reversed, with the onset phase of La Niña). Figure 10 shows the lead-lag correlation between the Niño-3 SST index and the two PC time series, the WF-index and the South Asian High Index (SAHI). In the case of EOF-1 and the WF-index, there is a significant correlation between the two indices and Niño-3 SST in the winter and spring immediately preceding the summer but no significant correlation with Niño-3 SST in the following winter. This is consistent with the idea that the positive phase of EOF-1 is associated with the El Niño decaying phase. On the other hand, both the PC time series for EOF-2 and the SAHI show significant correlations with Niño-3 SST in both the preceding and the following winter seasons. It follows, in agreement with Wang et al. (2008a), 
(a)

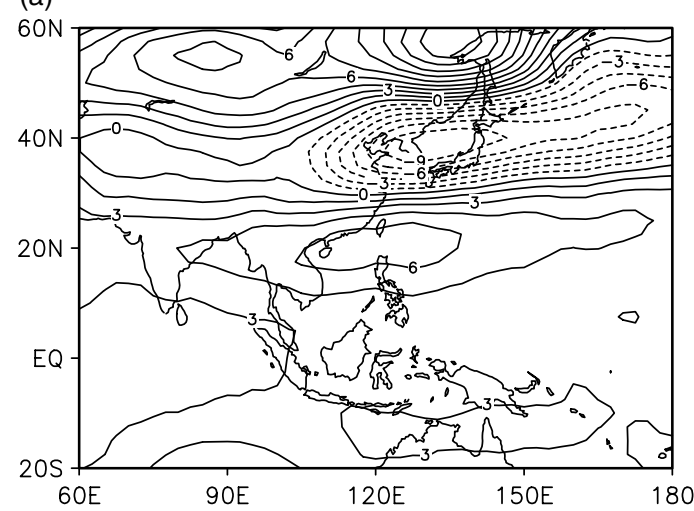

(c)

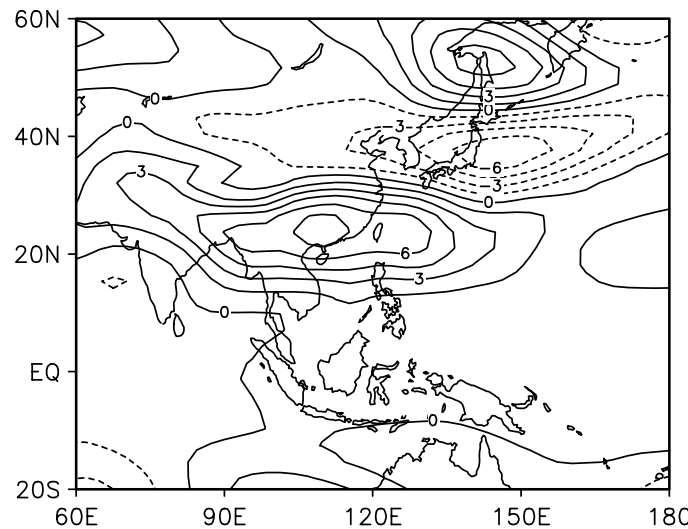

(e)

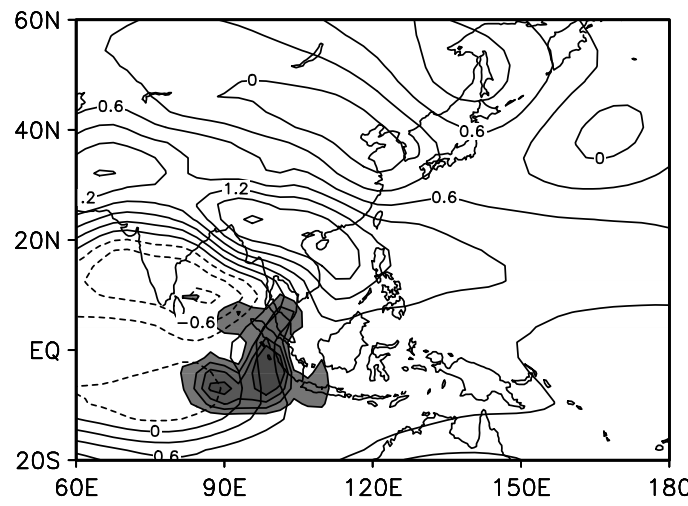

(b)

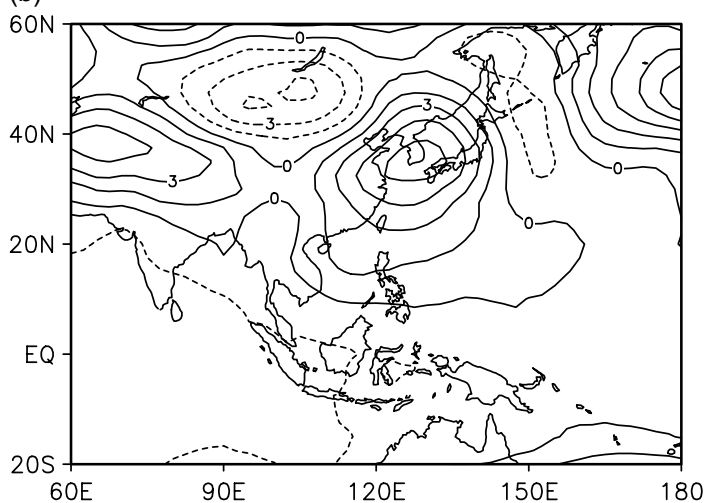

(d)

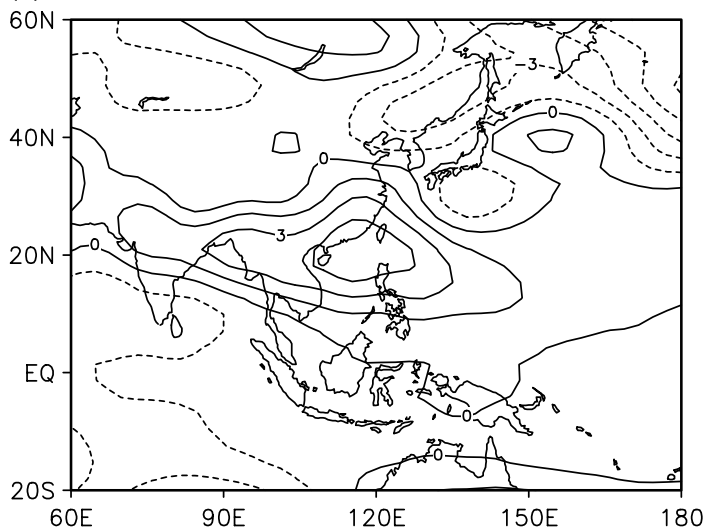

(f)

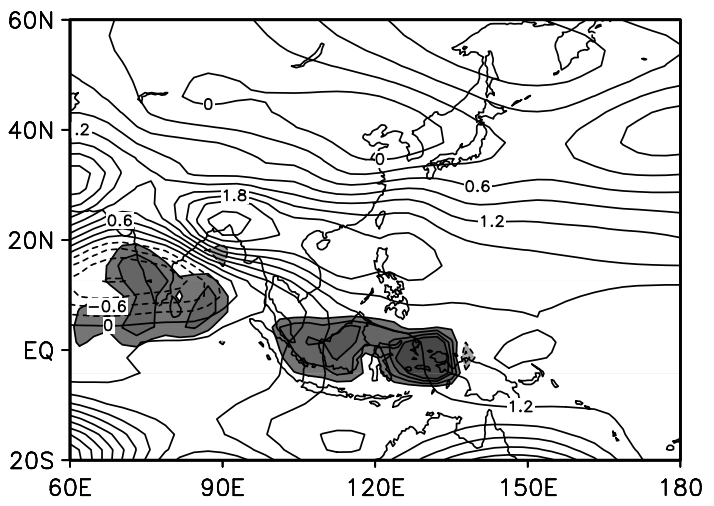

Figure 9. $500 \mathrm{hPa}$ geopotential height in the ERA-40 reanalysis data regressed against (a) PC1 and (b) PC2, and the response of the linear, dry dynamical model to the (c), (d) global and (e), (f) Indian Ocean/maritime continent 3-D diabatic heating (shaded area, shading as in Figure 5) regressed on PC1 (left column) and PC2 (right column). Contour interval for geopotential height in (a)-(d) is $1.5 \mathrm{~m}$, and $0.3 \mathrm{~m}$ in (e) and (f); contour interval for diabatic heating in (e) and ( $\mathrm{f}$ ) is $0.1 \mathrm{~K} /$ day.

that the positive phase of EOF-2, while also linked to the decaying phase of El Niño, is connected to the onset of La Niña events, consistent with the zonal wind anomalies along the Equator we have already noted in connection with EOF-2, and vice versa for the negative phase.

Figure 11 is the same as Figure 10 but for running crosscorrelations between the two PC time series and Niño-3 SST in different seasons. From this figure it is immediately apparent that the relationship between EOF-1 and Niño-3 SST in the previous winter has not been robust throughout the time period of the analysis (1958-2001). Indeed, it is only in recent decades (in particular, the period since 1979 studied by Wang et al. (2008a)) that the link between EOF-1 and Niño-3 SST in the previous winter can be found; prior to that time, no significant link was present. This result is consistent with Xie et al. (2010) who note a strengthening of the link between ENSO and the PJ pattern (to which EOF-1 is closely related) following the climate shift that took place over the Pacific Basin in the mid-1970s. (See also Wang et al. (2008b) who used a seasonal-reliant EOF analysis applied to the Asian-Australian Monsoon (A-AM) system to conclude that since the late 1970s, the overall coupling between the A-AM and ENSO has strengthened.) For EOF2, on the other hand, the link with Niño-3 SST in both the preceding and the following winter is robust throughout the study period. It is interesting, however, that in the case of EOF-2, we find evidence of a statistically significant link between EOF-2 and Niño-3 SST before the mid-1970s in the simultaneous summer and that this link weakened after that time. We noted in section 2 that of the two EOFs, it is EOF-2 that is linked to rainfall over the Indian subcontinent as measured by the All-India Rainfall Index (AIRI). It is 


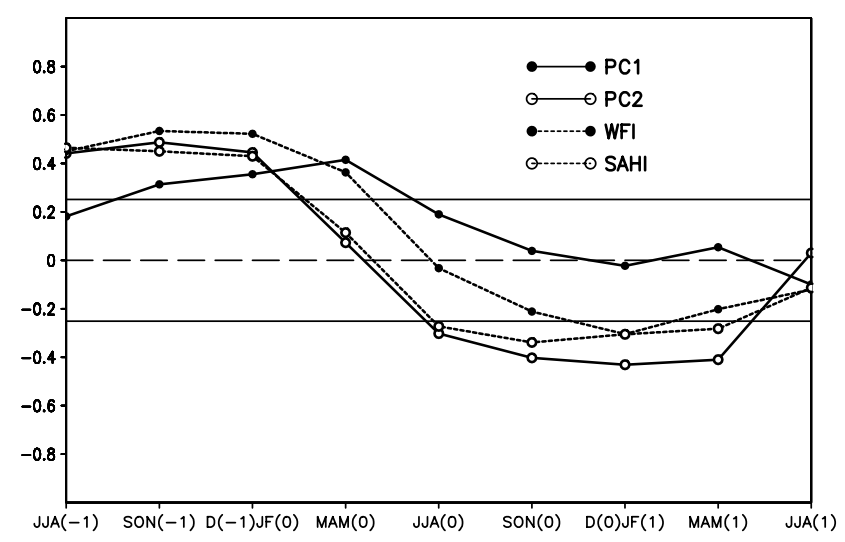

Figure 10. Lead-lag correlation between the Niño-3 sea-surface temperature (SST) index and the two PC time series, the WF-index and the South Asian High Index (SAHI) from JJA $(-1)$ to JJA(1). The two horizontal black lines represent the $90 \%$ confidence level based on Student's t test. 'JJA(0)' indicates the summer simultaneous with the MV-EOF analysis, ' -1 ' indicates the preceding year and ' 1 ' the following year.

(a)

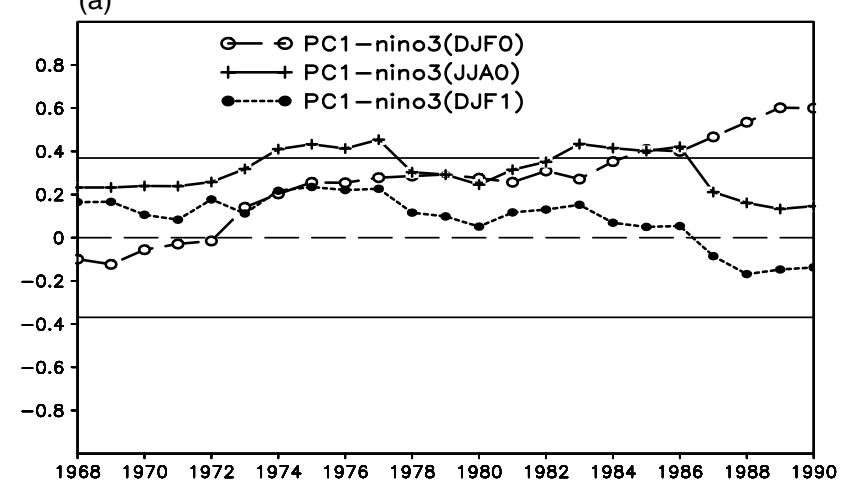

(b)

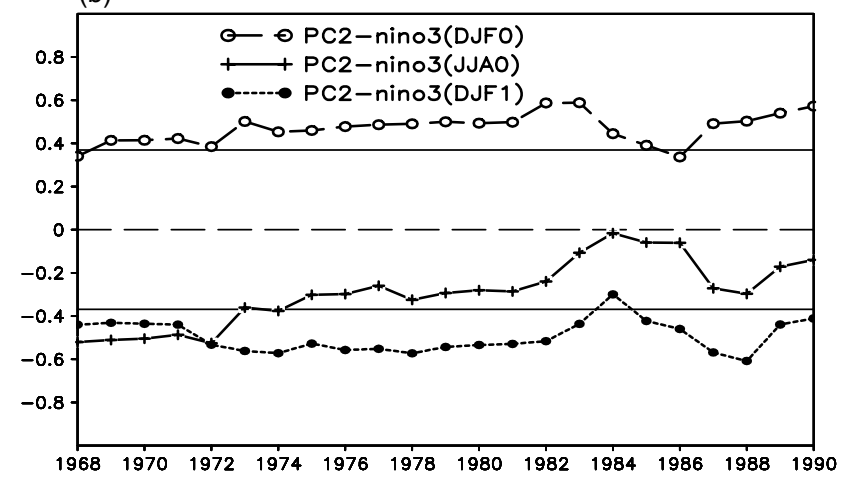

Figure 11. Same as Figure 10, but for 21-year running cross-correlations between (a) PC1 and (b) PC2 and Niño-3 SST. Niño3 (DJF0), Niño3 (JJA0) and Niño3 (DJF1) indicate the Niño3 indices in the previous winter, simultaneous summer and following winter, respectively. All time series were detrended separately in each 21-year period.

also well known that the link between AIRI and ENSO has declined significantly in recent decades (Kumar et al., 1999; Torrence and Webster, 1999). Kucharski et al. (2007, 2008) have shown that the change in the Indian monsoon-ENSO connection is due to the influence of SST anomalies in the tropical Atlantic Ocean, a factor that seems likely to play a role in the dynamics of EOF-2 as well.

Given the lack of robustness in the link between EOF-1 and ENSO, we can ask about the robustness of the connection between EOF-1 and the diabatic heating anomalies shown in Figure 5. Figure 12 shows that for the positive phase of both
EOFs, the diabatic cooling associated with the subtropical anticyclonic anomalies and, for EOF-1, the diabatic heating associated with the cyclonic circulation anomaly to the north, are indeed statistically robust features in each time window. On the other hand, the diabatic heating anomalies over the tropical Indian Ocean used to produce Figure 9 do not emerge as being statistically robust in the running crosscorrelation analysis (although, in the case of the positive phase of EOF-2, the anomalous heating over the maritime continent region is statistically significant in each time window). To investigate this issue further, we can also ask if there is a link between the variability associated with each EOF and global SST anomalies, and how that link might differ before and after the mid-1970s (Figure 13). We see that in the positive phase of EOF-1, a feature of both time periods is the presence of warm SST anomalies in the tropical Indian Ocean with stronger SST anomalies in the post- than in the pre-1979 period. It has been shown in several papers that warm SST anomalies in the tropical Indian Ocean can induce anticyclonic anomalies in the subtropical western Pacific, such as associated with the positive phase of EOF1 (Watanabe and Jin, 2003; Yang et al., 2007; Li et al., 2008; Xie et al., 2009, 2010). Xie et al. (2009) discuss in detail the 'Indian Ocean capacitor effect', introduced in Yang et al. (2007), whereby ENSO can influence the atmosphere in the summer following its spring decay phase through a delayed impact on Indian Ocean SST. Indeed, the capacitor mechanism can explain the link between ENSO in the previous winter and EOF-1 in the post-1979 period. Xie et al. (2010) show further that the appearance of the link between ENSO and the PJ-pattern (and by implication EOF-1) after the mid-1970s is because of the stronger and more persistent (into the following summer) influence of ENSO on tropical Indian Ocean SST after the mid-1970s climate shift. On the basis of Xie et al. $(2009,2010)$ and our discussion about the importance of anomalous diabatic heating over the tropical Indian Ocean based on Figure 9, we conclude that warm SST anomalies in the tropical Indian Ocean in the synchronous summer are an important factor in the dynamics of EOF-1.

Turning to the positive phase of EOF-2, we see that statistically significant warm SST anomalies in the tropical Indian Ocean are a feature only of the post-1979 period. Again, the warming trend of the Indian Ocean SST may play a role in this. In the pre-1979 period, it is rather the cold anomalies along the African coast that are now the statistically significant feature in the tropical Indian Ocean. It follows that the subtropical anticyclonic anomaly associated with the positive phase of EOF-2 cannot always be related to warm SST anomalies in the Indian Ocean, as for EOF-1, despite the fact, as we have seen when discussing Figure 9, that anomalous diabatic heating over the tropical Indian Ocean appears to be important in the dynamics of EOF-2. We have already noted that there is a link between EOF-2 and the Indian summer monsoon. In this context, another feature of interest in Figure 13 is the cold SST anomalies in the eastern tropical Pacific associated with the positive phase of EOF-2. These cold anomalies are statistically significant only in the pre-1979 period, consistent with the weakening of the connection between synchronous summer Niño-3 SST and both EOF-2 and the Indian summer monsoon noted when discussing Figure 11. (It should be noted that a running cross-correlation analysis shows that the correlation between EOF-2 and the AIRI changes little throughout the 
(a)

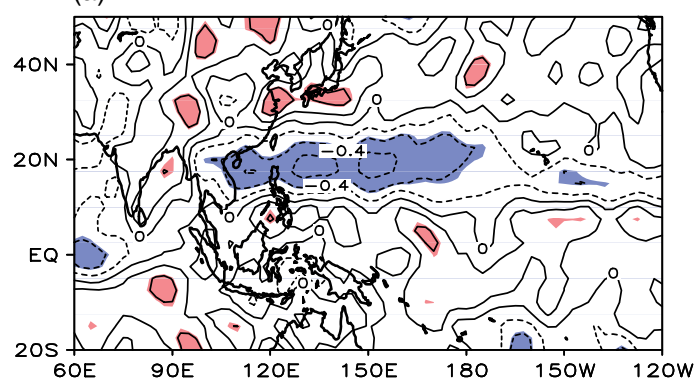

(c)

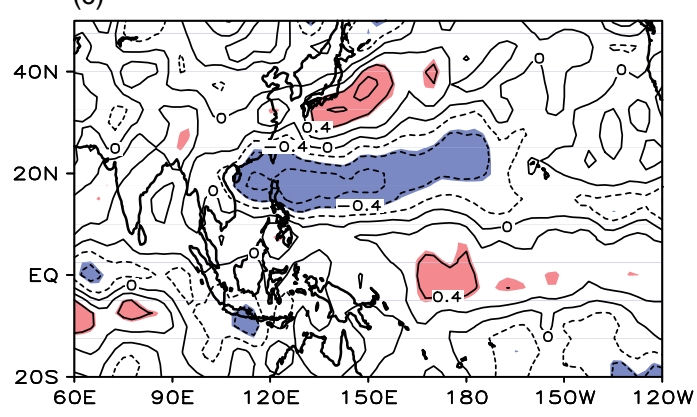

(e)

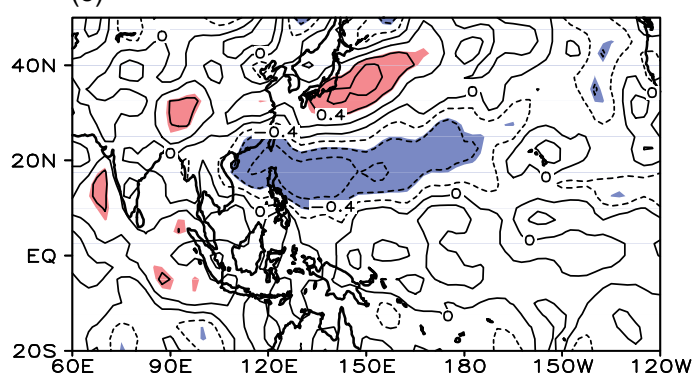

(b)

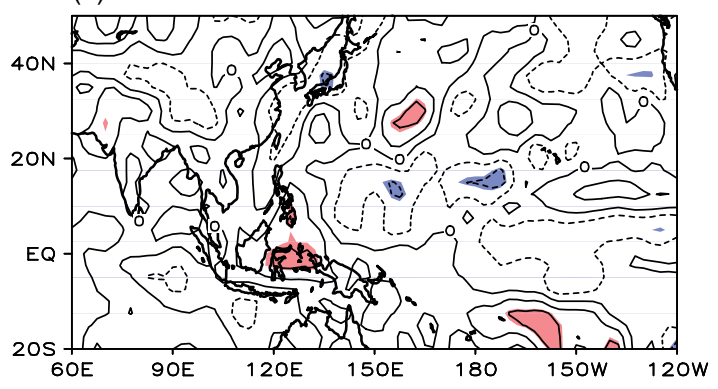

(d)

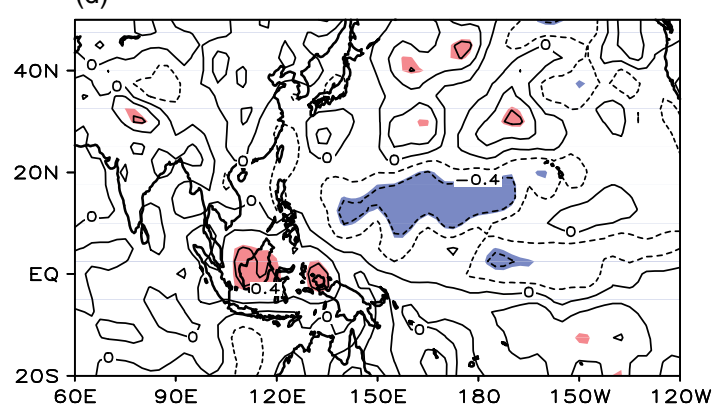

(f)

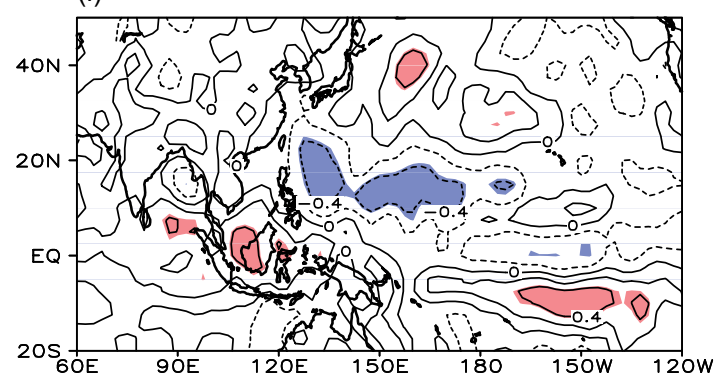

Figure 12. Correlation maps, using detrended time series, of diabatic heating against PC1 (left panel) and PC2 (right panel) for the 21-year period centred on (a), (b) 1971, (c), (d) 1980 and (e), (f) 1989. Coloured areas indicate correlation above the $90 \%$ confidence level (red/blue corresponding to positive/negative diabatic heating anomalies going along with the positive phase of the EOFs).

(a)
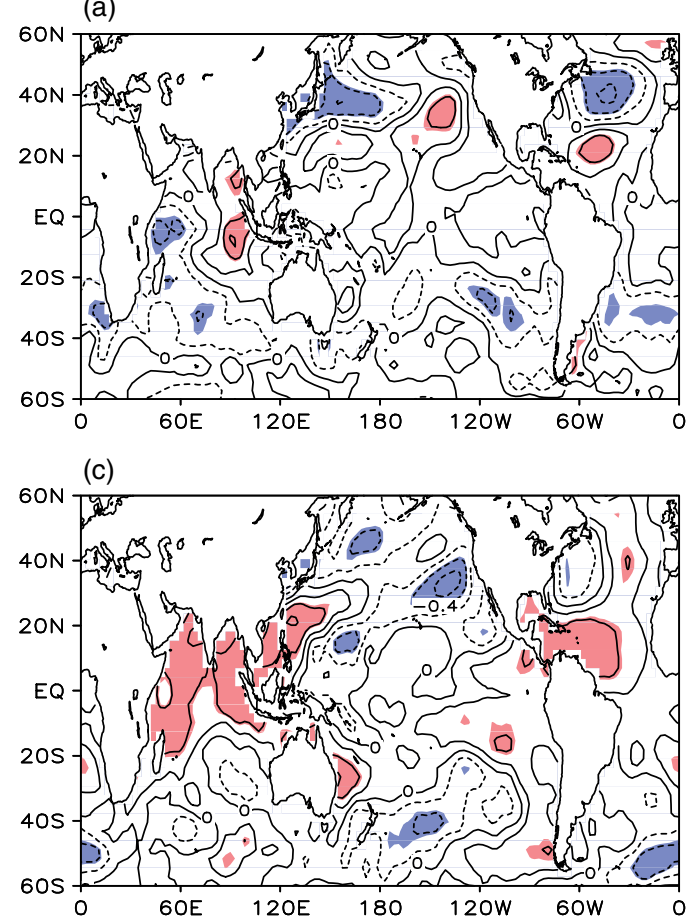

(b)

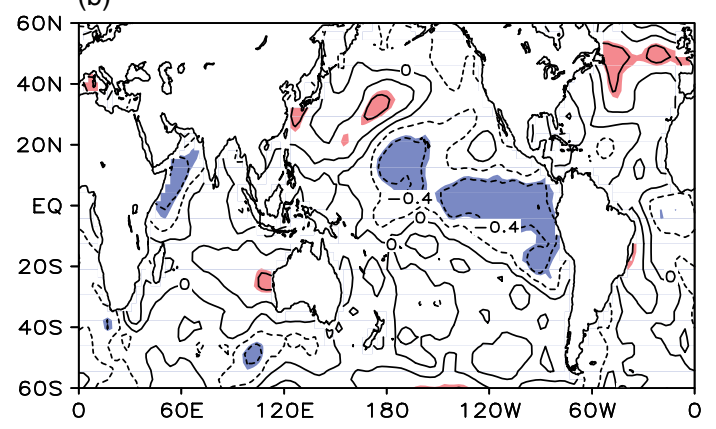

(d)

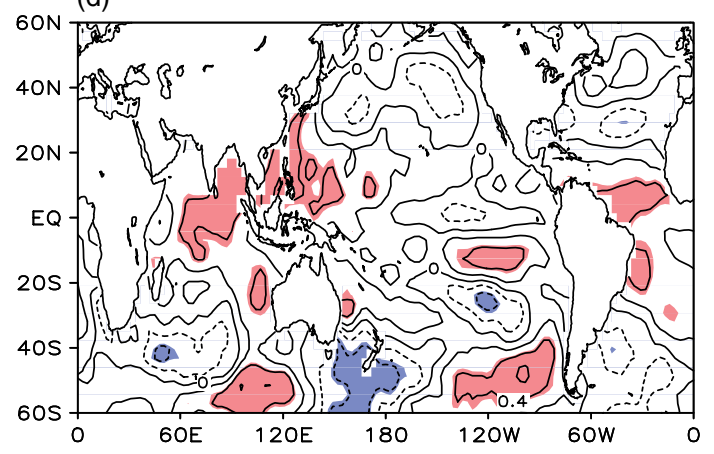

Figure 13. Correlation maps, using detrended time series, of global ocean SST against PC1 (left column) and PC2 (right column) in the simultaneous summer. (a)-(b) and (c)-(d) are calculated for the time periods 1958-1979 and 1980-2001, respectively. Coloured areas indicate correlation above the $90 \%$ confidence level (red/blue corresponding to warm/cold SST anomalies going along with the positive phase of the EOFs). 
study period.) It seems that rather than being directly linked to SST anomalies in the tropical Indian Ocean, the dynamics of EOF-2 is related to that of the Indian summer monsoon.

$\mathrm{Wu}$ and Wang (2002) have noted a change in the relationship between ENSO and summer rainfall in northern China and Japan following the mid-1970s climate shift. In particular, these authors note a change in the summer rainfall anomaly over eastern north China in the decaying phase of El Niño from above normal in the pre-1970s period to below normal in the post-mid-1970s. Figure 3 in their paper shows the circulation anomalies at $850 \mathrm{hPa}$ obtained by regression against the Niño-3 SST index for the previous winter in each of the time windows 1962-1977 and 1978-1993. Looking at the 1962-1977 period, the circulation anomalies bear a notable resemblance to those for our EOF-2, whereas during 1978-1993 they much more closely resemble those of our EOF-1 (see Figure 6(a) and (b)). We believe the change reflects the fact that in the post mid-1970s period, there was a close link between EOF-1 and ENSO in the previous winter, a link that was missing in the pre-1970s period when, instead, only EOF-2 shows a link with ENSO in the previous winter. Given that significant rainfall anomalies in northern China are associated with EOF-2 and not with EOF-1, the dominance of EOF-1 in the later period is consistent with the change in the link between ENSO and rainfall in eastern north China noted by Wu and Wang (2002).

Finally, we note the suggestion of a downward trend in the time series for EOF-2 shown in Figure 2. Such a downward trend is consistent with the 'south flood/north drought' pattern of precipitation variability that has emerged over eastern China in recent decades and has been noted by a number of authors (e.g. Yang et al., 2004; Huang et al., 2006; Wang et al., 2008c; Zhou et al., 2009). Another feature of the PC time series in Figure 2 is the suggestion for EOF- 1 of a change in character of the variability, with larger amplitude events after the mid-1970s climate shift. This change in character is consistent with the presence of stronger SST anomalies in the tropical Indian Ocean going along with EOF-1 in the post-1979 period (Figure 13) and also with the recent work of Xie et al. (2010) showing the strengthening of the influence of ENSO on Indian Ocean SST anomalies after the mid-1970s climate shift. A factor in the change in behaviour of both EOFs could be the upward trend in Indian Ocean SST noted by Hoerling et al. (2004). However, as noted by Li et al. (2008), the dynamics of the atmospheric response to the upward trend in Indian Ocean SST appears to be different from that associated with the interannual variability. Clearly future projections of trends in EASM rainfall are of considerable socio-economic importance and remain a topic for future research.

\section{Summary}

We have applied a multivariate EOF analysis to ERA-40 data from 1958 to 2001 in order to identify the main modes of variability of the East Asian Summer Monsoon (EASM). As noted by Wang et al. (2008a), the first EOF is captured using a simple index (the WF-index) that characterizes the meridional shear of the zonal wind at $850 \mathrm{hPa}$ across $20^{\circ} \mathrm{N}$ in the longitude range of China. Here we have shown that the second EOF is related to variations in intensity of the South Asian High, the dominant feature of the summer mean circulation in the upper troposphere. Both EOFs are characterized, in the positive phase, by anticyclonic circulation anomalies in the subtropical western Pacific east of China. In the case of the first EOF, the corresponding southerly wind anomalies extend across China only as far as the Yangtze River valley where this mode is associated, in the positive phase, with anomalously high rainfall in the Meiyu/Changma/Baiu rain band. In the case of the second mode, these southerly wind anomalies extend further north and are associated with enhanced rainfall over a broad region of northern China. Both EOFs are associated with wind and corresponding rainfall anomalies over the Indian subcontinent, although it is the second mode that is significantly correlated with the All-India Rainfall Index.

Both modes are associated with anomalies in diabatic heating and we have used a dry dynamical model, linearized about the June/July/August climatology, to show that the circulation anomalies associated with each mode are largely driven by the diabatic heating anomalies that go along with them. We have argued that anomalous diabatic heating over the tropical Indian Ocean plays an important role in the dynamics of both EOFs, especially EOF-1. In the case of both EOFs, the subtropical anticyclonic (positive phase) anomalies further north are amplified by the co-located anomalous diabatic heating anomalies, and in the case of the first EOF, the diabatic heating anomaly associated with the Meiyu/Changma/Baiu rain band also amplifies the co-located circulation anomaly. Overall, the model performance is less good at $200 \mathrm{hPa}$ than at $850 \mathrm{hPa}$, although the main circulation anomalies in the equatorial band are captured.

We have also investigated the link between the two EOFs and ENSO. Wang et al. (2008a) have argued that the first EOF is associated with the declining phase of ENSO while the second EOF is related to the onset phase of ENSO. Our results show that it is only in recent decades, in particular since the mid-1970s, that the first EOF can be linked with ENSO; prior to that time, no significant link can be found. A similar change in the connection between East Asian summer climate and ENSO has been noted by Xie et al. (2010) and has been explained by these authors in terms of the strengthened impact of ENSO on the tropical Indian Ocean in the post mid-1970s period. On the other hand, we find that the link between EOF-2 and ENSO in both the preceding and the following winter has been stable throughout the study period. A feature of EOF-2 is the presence of zonal wind anomalies along the Equator in the west Pacific that are consistent with the idea that this mode plays a role in initiating ENSO events. We also noted that warm SST anomalies in the Indian Ocean are a robust feature, throughout the study period, of the positive phase of EOF-1 and that anticyclonic circulation anomalies in the subtropical Pacific are associated with forcing from warm SST anomalies over the tropical Indian Ocean in many studies (e.g. Watanabe and Jin, 2003; Yang et al., 2007; Li et al., 2008; Xie et al., 2009, 2010). In the case of EOF-2, however, the link between Indian Ocean SST anomalies is not robust throughout the study period and we have suggested that the dynamics of this mode is linked instead to that of the Indian summer monsoon. Finally, it is clear that the interaction with the westerly jet stream is different for EOF-2 than for EOF-1. Indeed, the major difference between the two EOFs occurs in middle latitudes and cannot be explained in terms of the diabatic forcing from the Indian Ocean. The interaction with the westerly jet stream and both EOFs remains a topic for further investigation. 


\section{Acknowledgements}

We are grateful to two anonymous referees for their helpful comments and encouragement. Xuguang Sun is grateful to the Deutsche Akademischer Austausch Dienst (the German Academic Exchange Service) for support covering a threemonth stay at IFM-GEOMAR and also for support from the National Natural Science Foundation of China (40705028, 40730953) and the Research Fund for the Doctoral Program of Higher Education of China. R.J. Greatbatch, W. Park and M. Latif are grateful to continuing support from IFMGEOMAR that also facilitated this work. We thank Professor Xiuqun Yang of Nanjing University for his encouragement and support.

\section{References}

Ding YH, Chan JCL. 2005. The East Asian Summer Monsoon: An overview. Meteorol. Atmos. Phys. 89: 117-142.

Gill AE. 1980. Some simple solutions for heat-induced tropical circulation. Q. J. R. Meteorol. Soc. 106: 447-462.

Hoerling MP, Hurrell JW, Xu T, Bates GT, Phillips AS. 2004. Twentieth century North Atlantic climate change. Part II: Understanding the effect of Indian Ocean warming. Clim. Dyn. 23: 391-405.

Hoskins BJ, Rodwell MJ. 1995. A model of the Asian summer monsoon. Part 1: The global scale. J. Atmos. Sci. 52: 1329-1340.

Huang RH, Cai RS, Chen JL, Zhou LT. 2006. Interdecadal variations of droughts and floodings in China and their association with the Eas Asian climate system. Chinese I. Atmos. Sci. (in Chinese). 30: 730-743.

Kosaka Y, Nakamura H. 2006. Structure and dynamics of the summertime Pacific-Japan teleconnection pattern. Q. J. R. Meteorol Soc. 132: 2009-2030.

Kucharski F, Bracco A, Yoo J-H, Molteni F. 2007. Low-frequency variability of the Indian monsoon-ENSO relationship and the tropical Atlantic: The 'weakening' of the 1980s and 1990s. J. Climate 20: 4255-4266.

Kucharski F, Bracco A, Yoo J-H, Molteni F. 2008. Atlantic forced component of the Indian monsoon interannual variability. Geophys. Res. Lett. 35: L04706, DOI:10.1029/2007GL033037.

Kumar KK, Rajagopalan B, Cane MA. 1999. On the weakening relationship between the Indian monsoon and ENSO. Science 284: 2156-2159.

Li S, Lu J, Huang G, Hu K. 2008. Tropical Indian Ocean basin warming and East Asian summer monsoon: A multiple AGCM study. J. Climate 21: 6080-6088.

Liu J, Wang B, Yang J. 2008. Forced and internal modes of variability of the East Asian summer monsoon. Clim. Past 4: 225-233.

$\mathrm{Lu} \mathrm{R}$, Lin Z. 2009. Role of subtropical precipitation anomalies in maintaining the summertime meridional teleconnection over the western North Pacific and East Asia. J. Climate 22: 2058-2072.

Miller AJ, Cayan DR, Barnett TP, Graham NE, Oberhuber JM. 1994. The 1976-77 climate shift of the Pacific Ocean. Oceanography 7: 21-26.

Mitchell TD, Jones PD. 2005. An improved method of constructing a database of monthly climate observations and associated highresolution grids. Int. J. Climatol. 25: 693-712.

Nitta T. 1987. Convective activities in the tropical western Pacific and their impact on the Northern Hemisphere summer circulation. J. Meteorol. Soc. Jpn 65: 373-390.
Parthasarathy B, Munot AA, Kothawale DR. 1995. 'Monthly and seasonal rainfall series for all-India homogeneous regions and meteorological subdivisions: 1871-1994.' Research Report RR-065. Indian Institute of Tropical Meteorology, Pune 411 008, India.

Rodwell MJ, Hoskins BJ. 2001. Subtropical anticyclones and summer monsoons. J. Climate 14: 3192-3211.

Sampe T, Xie S-P. 2010. Large-scale dynamics of the Meiyu-Baiu rainband: Environmental forcing by the westerly jet. J. Climate 23: $113-134$.

Torrence C, Webster PJ. 1999. Interdecadal changes in the ENSO-monsoon system. J. Climate 12: 2679-2690.

Uppala SM, Kållberg PW, Simmons AJ, Andrae U, Da Costa Bechtold V, Fiorino M, Gibson JK, Haseler J, Hernandez A, Kelly GA, Li X, Onogi K, Saarinen S, Sokka N, Allan RP, Andersson E, Arpe K, Balmaseda MA, Beljaars ACM, Van De Berg L, Bidlot J, Bormann N, Caires S, Chevallier F, Dethof A, Dragosavac M, Fisher M, Fuentes M, Hagemann S, Hólm E, Hoskins BJ, Isaksen L, Janssen PAEM, Jenne R, Mcnally AP, Mahfouf J-F, Morcrette J-J, Rayner NA, Saunders RW, Simon P, Sterl A, Trenberth KE, Untch A, Vasiljevic D, Viterbo P, Woollen J. 2005. The ERA-40 re-analysis. Q. J. R. Meteorol. Soc. 131: 2961-3012.

Wang B. 1992. The vertical structure and development of the ENSO anomaly mode during 1979-1989. J. Atmos. Sci. 49: 698-712.

Wang B, Fan Z. 1999. Choice of South Asian summer monsoon indices. Bull. Am. Meteorol. Soc. 80: 629-638.

Wang B, Wu Z, Li J, Wu G, Liu J, Chang C-P, Ding Y. 2008a. How to measure the strength of the East Asia summer monsoon. J. Climate 21: 4449-4463.

Wang B, Yang J, Zhou T. 2008b. Interdecadal changes in the major modes of Asian-Australian monsoon variability: Strengthening relationship with ENSO since the late 1970s. J. Climate 21: 1171-1789.

Wang B, Bao Q, Hoskins BJ, Wu G, Liu Y. 2008c. Tibetan Plateau warming and precipitation changes in East Asia. Geophys. Res. Lett. 35: L14702, DOI:10.1029/2008GL034330.

Watanabe M, Jin F-F. 2003. A moist linear baroclinic model: Coupled dynamical-convective response to El Niño. J. Climate 16: 1121-1139.

Watanabe M, Kimoto M. 2000. Atmosphere-ocean thermal coupling in the North Atlantic: A positive feedback. Q. J. R. Meteorol. Soc. 126: 3343-3369.

Watanabe M, Kimoto M. 2001. Corrigendum. Q. J. R. Meteorol. Soc. 127: $733-734$.

Wu R, Wang B. 2002. A contrast of the East Asian summer monsoon-ENSO relationship between $1962-77$ and 1978-93. J. Climate 15: 3266-3279.

Xie S-P, Hu K, Hafner J, Huang G, Sampe T, Du Y, Tokinaga H. 2009. Indian Ocean capacitor effect on Indo-Western Pacific climate during the summer following El Niño. J. Climate 22: 730-747.

Xie S-P, Du Y, Huang G, Zheng X-T, Tokinaga H, Hu K, Liu Q. 2010. Decadal shift in El Niño influences on Indo-western Pacific and East Asian climate in the 1970s. J. Climate, in press.

Yang X-Q, Zhu YM, Xie Q, Ren XJ, Xu GY. 2004. Advances in studies of Pacific Decadal Oscillation. Chinese J. Atmos. Sci. (in Chinese) 28: 979-992.

Yang J, Liu Q, Xie S-P, Liu Z, Wu L. 2007. Impact of the Indian Ocean SST basin mode on the Asian summer monsoon. Geophys. Res. Lett. 34: L02708, DOI:10.1029/2006GL028571.

Zhang P, Yang S, Kousky VE. 2005. South Asian high and Asian-Pacific-American climate teleconnection. Adv. Atmos. Sci. 22: 915-923.

Zhou T, Gong D, Li J, Li B. 2009. Detecting and understanding the multi-decadal variability of the East Asian summer monsoon - Recent progress and state of affairs. Meteorol. Z. 18: 455-467. 